\title{
Estado, quantificação e agência: uma análise genealógica
}

\author{
Alexandre de Paiva Rio Camargo ${ }^{1}$ \\ ${ }^{1}$ Professor adjunto do Programa de Pós-Graduação em Sociologia Política da Universidade Candido \\ Mendes (PPGSP-UCAM). Rio de Janeiro, RJ. Brasil. \\ E-mail: alexandre.camargo.2009@gmail.com.
}

\section{INTRODUÇÃO}

To mundo moderno, espera-se que as qualidades das pessoas e das que envolvam alocação de recursos e que produzam efeitos sobre o destino dos indivíduos e grupos sociais. Qualidades resultam de percepções particulares e negociações de significado em interações locais, razão pela qual dificilmente inspiram consensos sobre a definição de uma situação ou sobre a necessidade e a conveniência de uma intervenção. Para que tal ocorra, é preciso que as qualidades sejam convertidas em quantidades, que fornecem protocolos de objetividade e, nas democracias liberais, fontes de controle do poder discricionário. Quantificar os fatos sociais permite exprimir e fazer existir, sob a forma numérica, o que antes só podia ser percebido por palavras (Desrosières e Kott; 2005).

Enquanto as palavras têm ressonância sempre contingente, os números permitem representar a seriedade e a dimensão de um acontecimento, uma vez que este é inserido em formas duráveis e séries estáveis. Assim, por exemplo, toma-se a qualidade de uma rodovia pela quantidade de acidentes que nela têm lugar; a legitimidade de uma eleição decorre, em parte, do número de eleitores presentes; a influência de um especialista na opinião pública corresponde ao número de entrevistas, participações em noticiários, citações e referências em colunas e artigos de jornais; o valor do trabalho intelectual é dado pelos indicadores de produção acadêmica. Algo semelhante se passa na indústria cultural: a qualidade de uma obra musical ou literária depende do número de cópias vendidas; o impacto de uma performance pública se depreende do número de espectadores ou, mais recentemente, de visualizações 
online; a influência de uma celebridade é diretamente proporcional ao número de seus seguidores nas redes sociais. Em revistas e jornais, a frequência com que certos temas se repetem nas seções de política, economia e comportamento, dia após dia, semana após semana, estabelece as condutas relevantes para uma vida de sucesso, assim como as habilidades necessárias para enfrentar as intempéries e os riscos da vida social.

Este breve preâmbulo aponta para a centralidade da quantificação, especialmente das estatísticas públicas, na organização da sociedade moderna. Cifras, indicadores, índices, porcentagens, taxas e médias compõem o arsenal de prova e inferência das elites técnicas e científicas, extravasando o âmbito de aplicação para o qual foram inicialmente criados e transformando-se em categorias de percepção de múltiplos e diferentes atores sociais. Apresentando-se como sinônimo de objetividade e certeza, os números e as classificações estatísticas por eles mediatizadas balizam a esfera pública, aderindo aos julgamentos e tipificações que as pessoas comuns fazem em diferentes situações da vida (Desrosières e Thévenot, 1988).

Mais do que um discurso sobre a realidade, a estatística é uma tecnologia de governo, o que a torna um objeto privilegiado para entendermos os contornos assumidos pela percepção de um fenômeno social - como a desigualdade -, e sua construção como problema público. Como objeto sociológico, a estatística requer cuidados metodológicos especiais. Devemos ler as matrizes e as tabelas como textos, mediante sua tradução em proposições e sistemas de hipóteses, expressáveis em linguagem verbal. Nessa direção, Otero observa que "dois quadros sobre níveis de mortalidade tabulados segundo a estação do ano ou segundo os grupos sócio-ocupacionais dos falecidos remetem a duas hipóteses científicas e a dois universos teóricos bem diversos: a mortalidade como fato climático ou como fato social" (2006: 47).

Avançando nesse raciocínio, podemos afirmar que um quadro tabulado segundo a distribuição do suicídio pela composição racial da população difere, radicalmente, de outro que tabula a participação relativa dos grupos de cor na renda e na escolaridade média. Essas diferenças se dão tanto em termos do universo teórico mobilizado, quanto da concepção de sociedade e agenda pública vigentes em cada caso. $\mathrm{O}$ mesmo exemplo nos remete a diferentes registros sobre a desigualdade, quer em relação às suas condições de possibilidade - inexistentes onde e 
quando a mortalidade é um fato climático -, quer em relação ao campo visual do que pode ser problematizado e governado em um dado momento: desigualdade de renda e segurança do trabalho, no caso da tabulação da mortalidade por grupos ocupacionais; desigualdade racial, no caso do cruzamento entre cor e escolaridade.

A presente reflexão é inspirada na sociologia da quantificação (Berman e Hirschman, 2018; Camargo e Daniel, 2021; Desrosières, 2008a; Diaz-Bone e Didier, 2016; Espeland e Stevens, 2008). Esse campo vem se formando durante os últimos anos impulsionado, em parte, pela multiplicação das práticas de quantificação da realidade sob o neoliberalismo, que será abordado aqui como um regime político de gestão da população (Dean, 1999; Foucault, 2009; Rose, 1999). Ao longo das últimas décadas, a pressão crescente pela incorporação de provas científicas nas decisões políticas, pela extensão da disciplina do mercado às organizações governamentais ou não-lucrativas e pela coordenação de diferentes atividades através de longas distâncias culturais e geográficas produziu um grande aumento nas formas de raciocinar, avaliar, medir e comparar com números (Espeland e Stevens, 2008).

Na esteira desse movimento, a sociologia da quantificação busca analisar os processos de produção e comunicação dos números, mapas e gráficos - enquanto representações visuais das informações numéricas -, em seus efeitos de poder sobre a sociedade. Segue as questões clássicas da sociologia, relacionando a quantificação à desigualdade social, às formas de avaliação e coordenação da ação, ao conhecimento social, ao conflito e à crítica, à racionalização da vida e à organização do trabalho; sem deixar de abordá-la também como objeto em si mesmo e de pleno direito. Essa perspectiva analítica se interessa tanto pelos processos de quantificação na ciência ou por ela orientados, quanto pelos processos situados na fronteira entre a política, a administração e a vida pública - como a implementação de tecnologias numéricas, os procedimentos de padronização e gestão burocrática e o processo decisório e a formação de sujeitos coletivos (Diaz-Bone e Didier, 2016).

Assim, este artigo partilha dessas orientações para colocar em debate questões como: o papel dos procedimentos de quantificação na construção do Estado e das rotinas sociais; as formas de governar a população através dos números; e as modalidades de crítica estatística da realidade, nos processos de mudança social. Para tanto, se vale das contribuições de Michel Foucault e dos governmentality studies sobre 
a indução estatística da agência social no liberalismo e no neoliberalismo, "regimes de governo" que produzem e consomem liberdades. Também se baseia nos postulados da sociologia pragmática francesa, em particular o conceito de "convenções de equivalência" e na ideia de "pluralidade das lógicas de ação", que permitem compreender a dupla natureza da estatística, como instrumento de prova e como instrumento de governo, proposta por Desrosières (1993). Em seguida, discute a obra deste autor, realçando sua tipologia das formas de Estado, que relaciona os modos de quantificar a realidade aos modos de governar a população (Desrosières, 2008b, 2014b). Finalmente, faz uso crítico deste modelo para esboçar uma genealogia dos níveis de reflexividade mediados e viabilizados pelos dispositivos numéricos.

Sua contribuição consiste em (re)pensar o Estado e a agência social transformadora a partir de uma síntese entre a perspectiva construtivista dos anglo-foucaultianos, que relacionam as formas de quantificação a outras tecnologias de indução das condutas, e a abordagem preconizada por Desrosières, que prioriza a ciência da estatística e seu papel na coordenação da vida social. Paralelamente, oferece uma revisão substancial dos estudos sociais da quantificação. Em particular, seus aportes sobre a construção do Estado e os determinantes da agência.

\section{QUANTIFICAR PARA GOVERNAR E CRITICAR}

Quantificar permite comunicar e estabilizar fatos e significados em redes amplas de atores e instituições. Isso porque os dispositivos estatísticos traduzem as formulações de saberes especializados, como as ciências sociais, em recursos cognitivos mobilizados pela consciência prática na existência social. Assim, por exemplo, a gênese do índice de preço em diferentes países foi marcada pela iniciativa, por parte de autoridades e especialistas, de monitorar a inflação e regular os comportamentos econômicos. De imediato, o novo dispositivo estatístico mostrou-se incapaz de defender os atores sociais do aumento dos preços - sua finalidade declarada. Isso se dá justamente porque eles foram socializados em uma nova cultura dos números, que lhes permitia manipular a diferença entre as unidades de contagem da economia erudita e as unidades de pagamento da economia ordinária, antecipando suas ações em vista da perda de valor do dinheiro. Diante da indexação da economia e dos salários, a retroação das estatísticas sobre os atores, em vez de conter, contribuiu para estimular a inflação (Neiburg, 2011). 
Nas perspectivas de Foucault $(2008,2009)$ e de Latour $(1988,2000)$, mapas, cartogramas, censos e estatísticas são abordados como tecnologias de governo à distância, porque respeitam a autonomia de esferas privadas e sugerem condutas adequadas a concepções particulares de bem-estar individual e coletivo. Nesse registro, a estatística seria uma tecnologia liberal de governo porque procede pela delimitação da autoridade e pela codificação de domínios da sociedade, povoados por indivíduos que agem de acordo com certos princípios de interesse e fora do escopo legítimo de uma intervenção direta, com seus próprios processos econômicos e dinâmicas de coesão. A estatística é vista aqui como um dispositivo de transferência da atividade governamental para a superfície da sociedade; e o faz estruturando o campo de ações possíveis e fornecendo aos atores normas e padrões para seus próprios julgamentos, aspirações e condutas (Rose, 1999: 48-49).

Autores situados no marco teórico dos governmentality studies, como Rose (1992, 1999), Miller (2001) e Dean (1999), dedicaram-se a analisar o elo constitutivo entre a quantificação da vida pública e o governo liberal. Os números se apresentariam como instrumento de realização da promessa democrática de alinhar o exercício da autoridade pública com as crenças e os valores privados dos cidadãos. Por um lado, os números impõem um freio ao poder discricionário de governantes e especialistas ao obrigar que escolhas políticas e decisões burocráticas se submetam a protocolos que as fazem parecer produtos de técnicas analíticas padronizadas. Por outro lado, o governo democrático requer cidadãos vigilantes e calculadores em relação aos efeitos do poder e aos riscos de suas decisões privadas, constantemente afetadas por pesquisas de opinião e de mercado que deslocam e quantificam as percepções de realidade (Rose, 1999). A quantificação crescente do mundo contemporâneo seria um fenômeno a ser compreendido por duas dimensões complementares que caracterizam os governos modernos: a vigilância mútua e a indução das condutas mediante liberdades e autonomias produzidas e consumidas pelo liberalismo.

Nesse sentido, algumas questões heurísticas tornam-se sociologicamente relevantes para pensar a relação entre quantificação, agência e mudança social. O que pode ser visualizado ou, inversamente, o que permanece obscuro em determinados momentos ou sociedades, quando olhamos para dispositivos como censos, mapas, gráficos, tabelas e diagramas, que formam o campo visual sobre o que e quem deve ser governado? Como a estatística produz sujeitos de governo, de 
trabalhadores e consumidores aos chamados grupos de risco? Como os números sugerem ou induzem as habilidades que se esperam deles? Como indivíduos e populações são levados a se identificar com determinados grupos, de maneira a se tornaram virtuosos e governáveis? Todas essas são questões sensíveis aos governmentality studies e à sociologia da quantificação, na medida em que privilegiam a dimensão material, visual e espacial do governo, e que chamam atenção para as cartografias de poder e autoridade. Assume-se que o sucesso de um regime de governo depende de como os atores se experimentam através das capacidades (como tomar decisões racionais), qualidades (como ter um emprego) e estatutos (como ser um cidadão ativo) por ele incentivados e favorecidos (Dean, 1999).

Em um registro inteiramente diferente, a sociologia da crítica de Boltanski (2009) considera a reflexividade dos atores sociais e sua capacidade de justificar suas ações e de mobilizar seu senso de justiça com vistas ao estabelecimento do elo societário. A distinção que o autor realiza entre o que chama de realidade, que "tende a se confundir com o que parece se manter por sua própria força", ou seja, com a ordem, e, de outro lado, o mundo, o fluxo de acontecimentos e experiências, cuja possibilidade não está contida na totalidade conhecida (Boltanski, 2009: 93). Tal distinção permite conceber a estatística como forma institucional que coloca em questão a realidade e abre caminho para o mundo. A lógica do risco encerra essas duas dimensões. Como tecnologia de domesticação do acaso, ele é pensado a partir do cálculo de probabilidades, com base em uma precisão mensurável, segundo formatos e provas relativamente estabilizados. Mas o risco também consagra a incerteza como princípio do conhecimento e da ação coletiva. Rejeita a pretensão à exatidão e ao controle dos acontecimentos, introduzindo o possível na ordem.

No realismo metodológico partilhado pelo pragmatismo, a relação entre os dispositivos estatísticos e a constituição da realidade se estabelece sempre de forma circular. Enquanto a eficácia da categorização repousa na base jurídica, previamente consolidada, o conteúdo numérico que a estatística confere às entidades sociais as inscreve em uma realidade concebida como independente das ações individuais e das decisões políticas (Boltanski, 2014). Por este motivo, a estatística se apresentaria como um dos principais mediadores da relação entre realidade e mundo, alinhando-se à crítica reformista, que leva em conta a resiliência das formas do Estado face ao fluxo dos eventos que perturbam a ordem. 
A crítica reformista pode se apoiar em instrumentos estatísticos baseados em formas preexistentes, principalmente ao comparar diferentes domínios da realidade e estabelecer correlações entre variáveis. Por sua vez, a posição radical e revolucionária enfatiza a interdependência dos elementos que compõem a realidade, negando a possibilidade de sua modificação sem a transformação, de uma só vez, do conjunto. Trata-se de uma modalidade de crítica que encontra grande dificuldade em recorrer à estatística, uma vez que deve se basear em provas que não foram objeto de mapeamentos e totalizações e que, portanto, se apresentam primeiramente à experiência na qualidade de singularidades e exceções, aproximando-se mais da estética e da arte do que das ciências sociais (Boltanski, 2014).

Vemos assim que, a depender da perspectiva teórica escolhida, a quantificação pode ser abordada ora como tecnologia de governo e dominação, ora como fonte criadora de públicos e coletivos sociais. Confere forma institucional a vontades, sentimentos e inquietações dispersas e, assim, formaliza a crítica que leva à reforma e à emancipação. Subjacente a ambas as vertentes - dos governmentality studies e do pragmatismo francês - encontra-se o interesse pela crescente e acelerada penetração das práticas de quantificação nos diferentes domínios da vida cotidiana, viabilizando a privatização dos riscos e seus efeitos nocivos sobre a intimidade, as relações de trabalho e a gestão da vida.

De fato, a produção de subjetivações e liberdades que, na verdade, camuflam a captura das iniciativas e das singularidades, jamais foi tão marcante e abrangente como na atualidade. Os números nunca foram tão dominados como no governo neoliberal. Os serviços públicos são comodificados e monitorados pela capacidade de satisfazer uma clientela formada por cidadãos, em uma relação que se reduz à eficiência e à utilidade; esvaziada do princípio de universalidade e proteção que até então caracterizavam o moderno Estado-nação. Tal mudança se torna possível graças ao benchmarking, o procedimento de quantificação não apenas das atividades dos agentes como também do seu ambiente organizacional.

Consequentemente, a ação social (que se desenvolve sempre em uma situação concreta) passa a ser reduzida ao seu resultado, tal como estabelecido por metas e patamares de performance previamente fixados em um ciclo indefinido e autonomizado de avaliações comparativas - os quais incutem um espírito competitivo e uma compulsão pelas 
"boas práticas" (Bruno e Didier, 2013: 13). Como afirmou Desrosières, "uma vez que os procedimentos de quantificação são codificados e rotinizados, seus produtos são reificados. Eles tendem a se tornar 'realidade' através de um efeito catraca, de reversão muito difícil" (2008a: 12). Constrangidos pelo benchmarking, os agentes são obrigados a alcançar objetivos quantificados e a intensificar indefinidamente seu desempenho na área definida pelo indicador.

O novo e perverso imperativo de avaliar cada atividade por uma só métrica considerada adequada constrange os atores a se reportar cada vez mais aos indicadores, e cada vez menos aos julgamentos baseados em competências adquiridas. É o que ocorre em variados casos, como a redução da segurança do trânsito à quantidade de acidentes e testes de consumo de álcool; ou, ainda, a dependência crescente dos profissionais de saúde em relação ao número de atendimentos - um dos critérios para a progressão de carreira e liberação de recursos aos hospitais.

Se o benchmarking depõe as habilidades de avaliação dos atores em circunstâncias consideradas únicas e singulares, a generalização da quantificação abre novas possibilidades de crítica à realidade e permite uma outra atitude em relação aos números públicos: a de conferir visibilidade às desigualdades produzidas pelo capitalismo global. Os movimentos sociais nunca utilizaram as estatísticas como instrumento de resistência como o fazem atualmente. É o que apontam a forte politização das classificações raciais; a disputa por quais categorias são contadas nas estatísticas criminais; ou as pressões contra a dominação econômica.

Tal quadro nos convida a realizar uma análise exploratória dos modos contemporâneos de raciocinar, valorar, medir e comparar com números, e que singularizam as formas de quantificar no neoliberalismo quando comparado a outros regimes de governo. Nas próximas páginas será esboçada uma genealogia das formas de reflexividade mediadas e viabilizadas pelos dispositivos de quantificação, de maneira a (re)introduzir o estranhamento em relação ao mundo crescentemente quantificado em que vivemos, abrindo um novo horizonte de crítica do presente. Trata-se, assim, de uma investigação preliminar sobre processos de longa duração, o que exige saber quais os níveis da agência e da vida social foram construídos progressivamente como domínios comensuráveis. 


\section{REGIMES POLÍTICOS E RAZÃO ESTATÍSTICA: A CONTRIBUIÇÃO DE ALAIN DESROSIÈRES}

Um dos fundadores da sociologia da quantificação, o francês Alain Desrosières (1940-2013), se notabilizou por sua abordagem radicalmente inovadora sobre a estatística, sempre realçando sua dupla dimensão de "instrumento de prova" e "instrumento de governo", presente desde seu trabalho pioneiro sobre a socio-gênese das nomenclaturas profissionais ${ }^{1}$. O livro já evidenciava a tensão que perpassaria toda sua obra, entre, de um lado, uma abordagem internalista dos procedimentos de recurso científico aos números e, de outro, a desestabilização da prova numérica através da denúncia de sua construção pelos grupos dominantes (Desrosières e Thévenot, 1988). A partir de então, suas reflexões foram profundamente marcadas pela ideia de multiplicidade das convenções de equivalência e de pluralidade das lógicas da ação, um dos principais postulados da economia das convenções (Boltanski e Thévenot, 1991; Thévenot, 1986). Desrosières enfatizava que toda a quantificação é necessariamente precedida por uma convenção a categorização de um fenômeno precede sua mensuração -, o que implica que a estatística deve ser concebida simultaneamente como convencional e real.

Essa concepção aparece formulada pela primeira vez em seu livro $L a$ politique des grands nombres (1993), no qual o autor realiza uma história sociológica da razão estatística, cuja inteligibilidade reside na oscilação permanente entre seus dois polos opostos e complementares: a prova numérica, que serve à descrição da realidade e, como tal, referência indisputável que precede os debates; e a atividade de Estado, que serve à prescrição e à ação sobre essa mesma realidade e, como tal, alvo de denúncia e desconstrução da pirâmide de equivalências que sustentam a distinção social. Tratam-se, portanto, de dois registros de linguagem de que resultam duas atitudes em relação à realidade que devem ser igualmente levadas em conta na análise sociológica: uma realista (objetivista) e outra relativista (construtivista).

Do ponto de vista do trabalho estatístico, essa dupla atitude se reflete na busca por criar objetos que permanecem, tanto por razões formais - fabricação de indicadores, classificações e modelos de representação coerente e realista da realidade -, quanto por razões sociais - a aspiração a uma legitimidade como convenção e na constituição da sociedade. Em seu conjunto, essas propriedades responderiam à eficácia 
da estatística como base para o elo societário: "Para que esses objetos (categorias, conceitos, medidas) sejam permanentes, é preciso que eles sejam baseados em convenções, que devem ser inquestionáveis para a vida seguir seu curso e, no entanto, discutíveis para que a vida possa mudar de rumo" (Desrosières, 1993: 398).

Em L'État, le Marché et les Statistiques ${ }^{2}$ (2008b), Desrosières concebe o conceito de "regimes políticos da estatística", aplicando o arcabouço epistemológico desenvolvido em La politique des grands nombres como solução teórica para uma articulação mais precisa entre os polos da prova e do governo. $\mathrm{O}$ texto propõe historicizar a ação pública por meio da vinculação entre tipos distintos de Estado, as diferentes formas de governar a população e as configurações das práticas estatísticas. De um lado, entende-se que o Estado não possui uma forma única e que suas ações não podem ser interpretadas a partir de uma mesma racionalidade de intervenção. De outro lado, as modalidades de ação pública se relacionam com os instrumentos materiais e cognitivos construídos historicamente pelo Estado e que viabilizam as intervenções.

Essa reflexão claramente se aproxima da perspectiva foucaultiana sobre os regimes de governo, especialmente no que diz respeito à circularidade entre o campo do saber (e dos números) e as modalidades de intervenção pública. Embora Desrosières só tenha tomado conhecimento das conferências de Foucault décadas depois da morte do filósofo - com a publicação tardia de seus cursos no Collège de France -, é possível perceber a mesma inquietação teórica de fundo: qual é a relação entre os instrumentos estatísticos e as formas de subjetivação e indução da agência social?

Há diferenças importantes, contudo. Como observaram Diaz-Bone e Didier (2016), Foucault vinculou as estatísticas em geral à governamentalidade neoliberal, deixando de lado as variações entre as técnicas estatísticas que correspondem a distintas modalidades de crítica da realidade - justamente o que interessava a Desrosières. Diferentes métodos estatísticos têm efeitos diferentes sobre a gestão da população, donde a importância de um programa de pesquisa destinado a demonstrar as associações entre os modos de quantificar e os modos de governar.

O modelo desenvolvido a partir de L'État, le marché et les statistiques (2008) oferece uma tentativa de resposta, identificando cinco tipos ideais de formas de Estado a partir de sua relação com a economia e 
a conduta econômica. Dessa maneira, as tecnologias do censo e das estatísticas de população e produção se ajustariam às necessidades do "Estado Engenheiro"; as estatísticas de preço fundamentadas na teoria econômica clássica acompanham o "Estado Liberal"; as estatísticas do trabalho, as pesquisas de orçamento das famílias operárias, as técnicas de cálculo de probabilidade para determinação do seguro social estão na base da racionalidade política do Estado Providencial; a contabilidade nacional, as pesquisas sobre consumo e emprego e as técnicas econométricas respondem às necessidades do "Estado Keynesiano". Sucedendo a crise dos dois modelos precedentes e imbricados, o "Estado Neoliberal" põe fim às técnicas de previsão e planificação apoiadas sobre o conhecimento macroeconômico. Em lugar disso, toma proveito da generalização das técnicas de benchmarking que repousam sobre o princípio das antecipações racionais e a promoção da competição entre os atores. E o fazem segundo metas e objetivos mensuráveis, e não mais segundo as relações concretas de que tomam parte (Armatte, 2014: 21).

Embora bastante fecunda nas possibilidades de análise que descortina, a abordagem proposta, como a maioria dos modelos de natureza tipológica, esbarra na dificuldade de articular formas abstratas e regimes históricos concretos e situados. É o caso do "Estado Engenheiro", que o autor define como fortemente hierarquizado e racionalmente organizado, ocupando o espaço da iniciativa privada no sentido de planificar as transformações estruturais de longo prazo através da produção de estatísticas demográficas e tabelas de intercâmbios entre setores industriais (Desrosières, 2008b: 41-44). O problema dessa definição é que ela permanece historicamente demasiadamente fluida, abrangendo tanto o colbertismo na França absolutista, quanto o regime de planificação soviética - no qual estatística aparece plenamente identificada com as instâncias superiores da burocracia e do dirigismo econômico, em sua acepção original de "ciência do Estado".

Reconhecemos a fecundidade do modelo, especialmente em relação à lógica político-cognitiva que preside e liga os modos de quantificar aos modos de governar a população em cada configuração ideal-típica. Teceremos um diálogo entre a abordagem sugerida por Desrosières e as reflexões de Foucault e dos governmentality studies sobre a biopolítica e as condições do governo mínimo que caracteriza o liberalismo (Foucault, 2009). Ou seja, a visão da estatística entendida como tecnologia de governo liberal, na medida em que ela delimita a autoridade pela 
codificação dos domínios da sociedade e pelo respeito a autonomia da esfera privada, induzindo condutas adequadas a concepções particulares de bem-estar individual e coletivo. O objetivo é tentar superar as limitações tipológicas por meio de uma análise genealógica, enfatizando a singularidade dos acontecimentos que ora sustentam, ora descontinuam os regimes de governo. Tal opção permitirá examinar os níveis da vida social progressivamente construídos como domínios de comensuração e as modalidades de crítica descortinadas por cada uma das configurações propostas por Desrosières ${ }^{3}$.

\section{A QUANTIFICAÇÃO NO ESTADO LIBERAL}

No Estado Liberal, a razão governamental se volta para a configuração do mercado como fonte de veridição dos processos econômicos e de autolimitação do poder político. O mercado, enquanto palco naturalizado da ação, coloca-se como limitação ao governo toda vez que este ensaia intervenções indesejadas, porquanto antinaturais, na ordem das coisas e dos interesses (Foucault, 2009: 44). É no espaço autorregulado do mercado que a ciência econômica vai buscar a essência do homo economicus - forma de sujeito que se supõe inscrita na natureza e, portanto, no devir histórico.

O sujeito ético do governo, orientado pela transparência do mercado, deve mostrar-se calculador e prudente quanto aos efeitos de suas escolhas e decisões, além de possuir consciência prática sobre as operações econômicas que promovam seus interesses. Nesse quadro, os indivíduos são levados a (re)conhecer os perigos que constituem a vida social, ameaçando as liberdades que o governo necessita para produzir o sujeito responsável e, assim, transferir a atividade governamental para a superfície da sociedade. Ao Estado Liberal cabe garantir os mecanismos de segurança e estimular uma educação do perigo, possibilitando aos indivíduos experimentarem-no cotidianamente: desde a literatura policial até o interesse jornalístico pelo crime; desde as campanhas de higiene até o enquadramento da sexualidade como fonte de degeneração do indivíduo, da nação e da raça. A partir de meados do século XIX, "o perigo se constituirá progressivamente como o correlato psicológico e cultural do liberalismo" (Foucault, 2009: 90-91).

No Estado Liberal, o governo econômico delimita os usos da estatística como regulador público, garantindo que as decisões econômicas não sejam amparadas na vontade ou na autoridade dos governantes, 
e sim nas regularidades que constituem a economia e a sociedade. A estatística, ao lado da unificação dos pesos e medidas e da harmonização do sistema de horários, origina um regime de informação baseado na quantificação, permitindo que sequências de atividades sejam sincronizadas no tempo e no espaço (Camargo, 2016: 85). Dessa maneira, as práticas estatísticas devem ser entendidas a partir do mercado como princípio de coesão social e de autolimitação do Estado, referenciando a consciência do perigo e a agência econômica do sujeito ético do liberalismo.

No primeiro caso, destacam-se as estatísticas criminais, demográficas e sanitárias das intervenções urbanísticas, que espacializam o crime, a pobreza e a doença como risco eminente da vida social. Em seu conjunto, essas estatísticas revelavam a medida do crime, da insanidade, da prostituição, da vadiagem e do suicídio. Fenômenos que antes eram considerados residuais e tratados nos termos voluntaristas da virtude e do vício e que, agora, se tornavam categorias de desvio a serem conhecidas e mensuradas por representarem uma ameaça à unidade da sociedade (Hacking, 1982). Ao lado dos romances policiais, que exploravam o cotidiano da criminalidade, a visualização em série de uma variada grade de fenômenos, antes inacessíveis à comparação, foi fundamental na conformação da noção eminentemente liberal de segurança. Uma noção inseparável da internalização da violência, que resultou da diminuição dos contrastes e excitações emocionais a que os indivíduos estavam sujeitos antes da pacificação dos espaços sociais (Elias, 1993).

No que diz respeito à produção de um ethos econômico capitalista, foram importantes os esforços de normatização do comércio internacional, destinados à regulação de tarifas aduaneiras e cambiais para possibilitar a gestão das moedas nacionais. Não por acaso, os Congressos Internacionais de Estatística, criados em 1853, foram impulsionados pela conviç̧ão de que uma estatística internacional do comércio faria ruir o protecionismo e as intervenções estatais no mercado, revelando que "o liberalismo foi a tendência de fundo do internacionalismo estatístico"4 (Gagnon, 2000: 193). A partir do final século XIX, com a necessidade de regular a concentração industrial e estabelecer um parâmetro à legislação antitruste, as estatísticas econômicas se tornam reflexivas, captando os efeitos da variação dos preços nos comportamentos de vendedores e compradores (Desrosières, 2008b: 46). 
A invenção do social como registro da sociedade ampliaria as possibilidades de ação à distância, fazendo do Estado o vetor fundamental de coordenação das atividades humanas e responsável por prevenir os males produzidos pela própria organização da sociedade: acidentes, incapacidades naturais, doenças hereditárias e contagiosas, desemprego. Longe de ferir o princípio do governo mínimo, a intervenção do Estado será justificada pela noção de dívida para com aqueles expostos às consequências nefastas da divisão do trabalho, seguindo o cânone do utilitarismo liberal: reparar danos e remediar males, de maneira a aumentar as chances coletivas de sucesso de cada um, através de seus próprios méritos (Camargo, 2016). Trata-se não de uma negação, mas de um desdobramento da racionalidade política do liberalismo que reconfigura as relações entre Estado, quantificação e agência social.

\section{A QUANTIFICAÇÃO NO ESTADO PROVIDENCIAL}

O Estado Providêncial corresponde à rearticulação da racionalidade política do liberalismo ante a invenção do social. Busca promover a socialização dos riscos produzidos pela divisão do trabalho por meio da organização da assistência e de dispositivos de promoção do emprego. Rose e Miller (1992) propõem que o "social" seja compreendido como terreno trazido à existência pelo próprio governo; um espaço de problemas inéditos e específicos, alvo de tecnologias e programas destinados a garantir objetivos sociais e econômicos: a reversão do declínio da natalidade; o controle da delinquência e do comportamento antissocial; a educação e a socialização familiar; as consequências sociais da insalubridade e as vantagens proporcionadas por uma população sadia; a integração dos cidadãos à comunidade moral da civitas.

Tribunais, reformatórios, escolas, clínicas, creches e maternidades estão entre as novas instituições que vinculam as capacidades fiscais e burocráticas do Estado ao governo do social. De igual modo, dispositivos como o seguro social, o acidente de trabalho, a cartilha de higiene escolar e as estatísticas de desemprego e de orçamento familiar permitirão ligar as aspirações das autoridades à vida cotidiana dos indivíduos.

O seguro social foi a tecnologia de governo, gerada em resposta à crise provocada pela tensão entre capital e trabalho, que fermentou o ambiente revolucionário da segunda metade do século XIX. Constituiu a base a partir da qual se edificariam os elementos do Estado 
Keynesiano: aposentadoria por idade e tempo de trabalho, auxílio-desemprego e assistência social. Envolvendo os sindicatos de trabalhadores assalariados, as pesquisas de orçamento das famílias operárias e sobre os bens de consumo se estabeleceram investindo as relações sociais em formas estatísticas capazes de fornecer uma linguagem para a expressão das reivindicações e negociações resultantes dos conflitos de classe (Desrosières, 2014a: 55).

Nesse quadro, as práticas estatísticas serão redirecionadas para a produção de novos espaços e sujeitos de governo, voltando-se para a indexação dos salários, a dimensão do desemprego e o custo de vida. Cabe destacar aqui a construção estatística do fenômeno do desemprego e da figura do desempregado. Se durante a maior parte do século XIX os economistas políticos viam no desemprego um fenômeno temporário, devido à impossibilidade de equilíbrio entre a oferta e a demanda, os anos 1880 e 1890 assistiram à consagração do termo "desempregado" como sinônimo da pessoa que não trabalha contra a sua vontade. Introduzido por Alfred Mashall, o "desemprego" foi logo definido como "a quantidade total de força de trabalho humana não empregada na produção da riqueza social" (Hobson apud Alberti, 2011: 2). Com este sentido preciso, "desempregado" tornou-se categoria recorrente em censos de população e em surveys periódicos, outra novidade inaugurada pelos departamentos nacionais do trabalho.

Os primeiros censos nos quais aparecem os desempregados foram os dos EUA (1880), da Alemanha (1895), da França (1896) e da Itália (1901). Dois aspectos devem ser ressaltados. Primeiro: foram esses levantamentos, que traziam a definição do desemprego como condição involuntária, que permitiram costurar pela primeira vez a distinção entre população economicamente ativa e inativa, alocando os desempregados como parte do primeiro grupo. Segundo: a compilação de dados regulares sobre a temática passou, também de forma inédita, pela cooperação entre as agências governamentais e os sindicatos de trabalhadores, os quais repassavam os registros das atividades de seus filiados visando receber o auxílio-desemprego e outros benefícios correspondentes, igualmente recentes (Camargo, 2016: 80).

O fato de que a fiabilidade desses dados seja bastante criticada em nada compromete os pontos que nos interessam mais de perto: o início do monitoramento regular do desemprego; a construção do desempregado como posição de sujeito a partir das séries estatísticas; sua 
vinculação a efeitos jurídicos concretos (benefícios e penalidades); e o aprofundamento da interdependência através da expansão do jogo segurança/liberdade para o trabalho como novo campo visual do governo. Desse modo, a solidez e os usos da informação estatística são ampliados por meio da tradução de interesses e da organização da ação em rede, envolvendo os patrões, os empregados, seus respectivos sindicatos, as agências governamentais, a burocracia estatística e os analistas sociais, entre outros (Camargo, 2016: 81).

Portanto, ao lado do desenvolvimento de toda uma maquinaria de gestão de pessoal e provisão de bem-estar, como as novas instalações de saúde, os espaços de recreação e o apoio a poupanças e empréstimos, a estatística foi uma das tecnologias fundamentais de transformação do lugar de trabalho em um domínio social. Em conjunto, os novos recursos deslocaram os conflitos políticos do lugar de trabalho, transformando-o em um espaço de distribuição de riscos e prevenção de acidentes (Rose, 1999: 126). Como bem colocou Donzelot (1994: 121-177), um dos efeitos mais importantes do seguro foi a desdramatização dos conflitos sociais, ao eliminar o problema de atribuição da responsabilidade pelas origens dos males públicos e reduzir o impasse a uma questão de opção técnica, entre diferentes parâmetros, para otimizar empregos, salários e investimentos.

\section{A QUANTIFICAÇÃO NO ESTADO KEYNESIANO}

O Estado Keynesiano se diferencia do Estado Providencial pela escala industrial dos mecanismos de gestão do social e pela capacidade de vinculação de uma extensa variedade de pontos locais a um centro de governo e de cálculo, o que amplia as possibilidades de monitoramento populacional. Agências de emprego, clínicas de reabilitação, postos de saúde, tribunais, escolas, asilos e fábricas tornam-se espaços institucionais de identificação de homens, mulheres e crianças como indivíduos patológicos. Se antes esses espaços se limitavam a prescrever medidas reformativas, agora rastreiam os grupos de risco beneficiados com políticas de proteção, mobilizando assistentes sociais e outros especialistas em uma rede visível (e sujeita à intervenção normalizadora) amparada em uma burocracia da pedagogia e do cuidado. (Rose, 1999: 131-133).

Do ponto de vista da economia e da agência econômica, novos indicadores são inventados, segundo um princípio de otimização conjunta das estratégias de regulação, tornando a economia compatível com 
a gestão do social. A principal inovação reside na apresentação da riqueza e da produção como um todo articulado em fluxos macroeconômicos, suscetíveis de serem mensurados e religados em tabelas contábeis teoricamente coerentes e exaustivas (Desrosières, 2008b: 50). Esse fenômeno é mais bem simbolizado pela emergência da contabilidade nacional. Distinguindo-se das antigas estimativas da receita dos países, características do Estado Liberal, as contas nacionais investem o espaço nacional na forma da grande empresa, calculando diferentes variações de grandeza e visualizando as atividades humanas como um fluxo de serviços e bens - inovação possibilitada pela introdução da pesquisa por amostragem 5 .

A adoção da amostragem nas pesquisas estatísticas consistiu muito mais do que uma mera inovação técnica. Em primeiro lugar, ao cobrir um universo muito mais restrito de pessoas e situações, a amostragem representativa permite reduzir os elevados custos de uma pesquisa exaustiva de base territorial e sincrônica (como o censo) além de disponibilizar muito mais rapidamente seus resultados. A dependência do censo como única fonte de informação dos movimentos da população cede lugar a pesquisas contínuas e mensais de inflação (índice de preço), desemprego (pesquisa mensal de emprego), consumo (orçamento familiar), crescimento industrial (matriz de insumo-produto) e desenvolvimento social (PIB per capta), que viabilizam o monitoramento constante dos fluxos segundo a racionalidade da empresa e em escala nacional.

Em segundo lugar, embora as pesquisas por amostragem tenham no censo a sua fonte de informação primária, elas evidenciam uma revolução político-cognitiva na quantificação da realidade. O realismo metrológico do censo se baseia na visão do território nacional como uma totalidade orgânica e no reconhecimento de sua divisão interna, em distritos censitários e regiões demográficas. Toda a contagem de subunidades nesse conjunto remete à média nacional, que define $o$ que é acidental e/ou excepcional. Já a amostragem aleatória autonomiza a parte em relação ao todo na medida em que desterritorializa as condições de observação das relações econômicas e sociais. Enquanto o censo é marcado pela exaustividade e pela exatidão da contagem, que denotam uma concepção de verdade vinculada à correspondência com a realidade, a amostragem tem sua autenticidade garantida pelo seu grau de precisão, por meio do controle da margem de erro, sugestivamente chamada de "intervalo de confiança". No lugar da 
correspondência, persegue-se uma verdade aproximada em favor do nível de significação que os dados podem imprimir à ação pragmática do Estado e dos atores econômicos.

Segundo Desrosières (1988: 93-112), a política da precisão mensurável, que está na base da amostragem, só emerge quando as técnicas locais de administração dos problemas públicos, típicas dos regimes anteriores, cedem lugar ao gerenciamento de um Estado que se apresenta como o centro que subordina e hierarquiza as periferias do poder. Antes, os agentes econômicos contavam com um conhecimento geral e difuso das condições em que operavam para prever cenários e antecipar situações. Agora, suas ações são constantemente reorientadas por um repertório variado de informações flutuantes sobre as oportunidades de investimento e a disponibilidade dos recursos que garantem as políticas de coletivização dos riscos - como o "pleno emprego", o seguro social, a educação universal e a assistência a idosos, crianças, deficientes e alienados.

Os efeitos da revolução da amostragem sobre a performatividade dos números e as condições de reflexividade serão sentidos em diferentes níveis. De um lado, as pesquisas que revelam a desigualdade de mobilidade entre as categorias socioprofissionais passam a orientar as escolhas de carreira e as estratégias ascensionais dos atores sociais. De outro lado, os indicadores de inflação e custo de vida tornam-se ponto de passagem obrigatório para as opções de consumo das famílias, para a pressão sindical por indexação salarial e para a construção da crise econômica como fato social.

O Estado planejado e planejador figura aqui como o principal garantidor da liberdade individual contra as patologias e os riscos que cercam a vida social. A crítica neoliberal desqualifica essa associação entre liberdade e regulação, acusando a responsabilidade solidária de produzir uma cultura da dependência que inibe a capacidade do indivíduo empreender e otimizar seu bem-estar e qualidade de vida. Por meio da nova forma social da "comunidade" - um intermediário entre o indivíduo e a sociedade -, os sujeitos serão produzidos pelo consumo de identidades às quais são ligados valores e pertencimentos definidos por etnia, estilo de vida, sexualidade, filiações políticas, etc. (Rose, 1999: 135-136). Na crise do Estado Keynesiano, as condutas individuais deixam de ser socialmente determinadas, enquanto o social se 
fragmenta em uma miríade de comunidades entendidas como o novo terreno em que as disposições, culturas e patologias dos indivíduos podem ser problematizadas e reformadas.

\section{A QUANTIFICAÇÃO NO ESTADO NEOLIBERAL}

O Estado Neoliberal é caracterizado pela generalização da forma econômica do mercado para o conjunto da sociedade, funcionando como princípio de inteligibilidade das relações sociais e dos comportamentos individuais (Foucault, 2009). A formalização da sociedade, com base no modelo da empresa, se torna um instrumento que enforma a administração ao fornecer um novo fundamento ao poder que engloba e ultrapassa a antiga crítica política e jurídica ao "excesso de governo". É que o mercado deixa de constituir o princípio de auto-limitação do governo, como ocorria no liberalismo clássico, para se tornar uma espécie de tribunal por meio do qual os comportamentos não-econômicos - como a criminalidade, as decisões judiciais, as patologias sociais e a vida familiar - passam a ser lidos pela chave analítica da economia.

Por conseguinte, amplia-se a responsabilidade de indivíduos, famílias e comunidades, uma vez que a minimização dos riscos se torna um aspecto das escolhas que fazem enquanto consumidores, clientes e usuários de serviços. No século XIX, a prudência limitava-se à procriação ao comportamento industrioso, à sobriedade e à frugalidade doméstica. Na governamentalidade neoliberal, o sujeito virtuoso e calculador precisa monitorar os riscos relacionados aos mais diferentes domínios da vida social: a saúde física e mental, a vida sexual, a dependência química e afetiva, o desemprego, o desamparo na velhice, o desempenho escolar, o fracasso profissional, a baixa autoestima, a exposição ao crime, entre outros (Dean, 1999).

De garantidor da vida pública e gestor dos riscos que a constituem, o Estado passa a facilitador das virtudes que os indivíduos devem possuir enquanto cidadãos ativos, capazes de fazer escolhas para satisfazer seus interesses e viver de forma prudente. A ação do poder público tem por finalidade o empoderamento dos sujeitos por meio de técnicas de promoção da autonomia, tais como o exame de consciência, a preocupação com a autoestima, a pedagogia alternativa e a retórica da voz e da representação direta, que passam a reconfigurar o papel das instituições certificadas pelo Estado. Escolas, hospitais, organiza- 
ções, agências de emprego e associações de classe são transformadas em parceiras na empresa governamental de realização do bem-estar (Rose, 1999: 147).

Trata-se aqui de deslocar a autoridade dos especialistas, criticados por promoverem exclusões e deslegitimarem formas locais de conhecimento, infantilizando pacientes, alunos, desempregados, aposentados e toda sorte de assistidos pela burocracia da pedagogia e do cuidado. Os especialistas serão treinados e avaliados por sua capacidade de observar as necessidades de seus públicos e de respeitar o direito ao corpo e o princípio da autodeterminação, que presidem a necessidade de explicação dos protocolos e de compartilhamento dos riscos envolvidos em cada tomada de posição (Rose e Miller, 1992).

O arrefecimento da dominação burocrática e profissional reflete o desmembramento do Estado em múltiplas agências de provisão de serviços, cuja qualidade deve ser alcançada pelas mesmas práticas da gestão empresarial, e constantemente orientada pelas necessidades de seus consumidores. $\mathrm{O}$ caso das instituições estatísticas é emblemático. Os números públicos se tornam um artigo relevante de consumo e as agências produtoras de dados oficiais são redefinidas como fornecedoras de serviços determinados pelas necessidades de seus usuários. Transformam-se em empresas que oferecem produtos em um mercado formado por clientes sensíveis ao preço e à qualidade. Pressiona-se pelo abandono de pesquisas que não atendem à demanda dos consumidores por informação, julgadas caras e ineficientes pela política de restrição orçamentária. Enquadra-se o trabalho estatístico pelos princípios do marketing e da qualidade total (que impõem um calendário de datas pré-fixadas para a publicação das pesquisas) e manuais de boas práticas para sua validação: acessibilidade, transparência, independência, objetividade e sigilo são algumas das exigências que os estatísticos devem fazer face diante do desmembramento do Estado e do recuo da confiança na autoridade profissional (Beaud e Prévost, 2010).

A conversão dos bens públicos em serviços oferecidos a clientelas não só reconfigura o Estado como altera as formas de subjetivação. A sujeição se torna condição da liberdade, como sugere o exemplo do desempregado, que só recebe auxílio se empenhar-se em procurar trabalho e em corresponder ao perfil desejado pelas empresas. $\mathrm{O}$ suporte e a orientação recebidos pelo consumidor de serviços de agências de emprego precedem e induzem a liberdade a ser exercida pelo traba- 
lhador. Trata-se de um regime de governo marcado por práticas de liberdade que continuamente associam sujeição e subjetivação. Por um lado, promove o contrato, a consulta, a negociação, a parceria, empoderando as formas de agência e escolha de indivíduos, famílias, consumidores, profissionais, vizinhanças e comunidades. Por outro lado, estabelece as normas, as metas, o controle de qualidade, os indicadores de desempenho e os padrões de boas práticas para monitorar, medir e tornar calculáveis as performances dos mais diferentes atores e agências (Dean, 1999: 165).

Esse último ponto constitui a principal diferença entre as práticas de quantificação anteriores e as da governamentalidade neoliberal. Enquanto as estatísticas do Estado Keynesiano ensejavam a luta contra o desemprego e a defesa do poder de compra das famílias, novos instrumentos de mensuração se difundem pela administração pública para governar seus próprios funcionários e as relações que mantêm com seus usuários-clientes - cidadãos, contribuintes, aposentados e estudantes. A retroação sobre a agência se amplia significativamente com o benchmarking, ou seja, a avaliação e classificação segundo metas e patamares de performance, o que é viabilizado pela difusão da teoria das antecipações racionais e pela adoção de mecanismos de incitamento da conduta.

Segundo essa teoria, as políticas públicas tendem ao fracasso quando os atores integram, em seus esquemas cognitivos, os efeitos antecipados das decisões públicas. Um entendimento que está na base da decomposição do Estado em diversos centros de direção, geridos como empresas, alvos dos mesmos dispositivos de incitamento por objetivos que orientam os demais atores econômicos. Modelos econométricos permitem separar os efeitos esperados das políticas e isolá-los dos resultados alcançados, os quais são aprimorados pela pressão de estímulos fiscais e códigos de boas práticas (Desrosières, 2014b).

O benchmarking é uma tecnologia de governo, uma arte específica de condução das organizações sociais. Segundo Bruno e Didier (2013: 18), se caracteriza por uma sequência de ações: 1) definição de uma série de indicadores estatísticos que medem as performances de um determinado número de atores e atividades pré-identificados; 2) fixação de um objetivo quantificado a ser alcançado, para cada indicador empregado; 3) delimitação do intervalo de tempo durante o qual os 
atores se esforçam por realizar aqueles objetivos; e 4) planejamento de encontros para comparar as performances obtidas e definir as metas do próximo ciclo.

Nesse novo regime de quantificação pública, os indicadores dependem dos próprios agentes para quantificar e monitorar suas atividades. Afinal, quem pode saber quantos artigos um pesquisador publicou em um determinado ano, que não ele mesmo? Quem pode saber quantas intervenções realiza uma patrulha de polícia em um dia, que não a própria polícia? Quantos pacientes foram atendidos em um plantão, senão os médicos plantonistas? Os avaliados que se tornam seus próprios avaliadores, contabilizando e reportando os dados que lhes concernem. Trata-se de uma diferença fundamental entre os indicadores produzidos pelo INSEE ou pelo IBGE, sobre a conjuntura ou o índice de preço, e os indicadores que os atores produzem sobre si para fins de otimização da gestão. No primeiro caso, os números resultam da observação de uma realidade exterior; no segundo, de um olhar dirigido para si mesmo de maneira contínua e autorreferencial. Revela-se aí a tensão essencial do novo sistema, que depende de confiar nos que estão em condição de produzir, porque sabem, e, ao mesmo tempo, deles desconfiar, em virtude da ameaça permanente de fraudes e mentiras (Bruno e Didier, 2013).

Do ponto de vista organizacional, as fraudes e irregularidades se tornam toleráveis desde que não custem mais caro do que a supressão do aparato de vigilância permite economizar. A prerrogativa dos avaliadores em se avaliar é apresentada como uma vantagem, uma arma antiburocrática, já que os assalariados ganham uma margem expressiva de iniciativa, supostamente se libertando das amarras da hierarquia e do formalismo dos regulamentos. Similarmente, por ser basear na adesão voluntária e por remunerar o trabalho em função dos resultados - e não por horas trabalhadas -, o novo regime traria a vantagem adicional de valorizar o mérito e a capacidade criativa, quando, na verdade, os agentes são submetidos a uma dominação mais perversa e sutil do que a antiga ingerência do superior hierárquico, da lei e do poder soberano.

Isso porque, ao contrário das estatísticas públicas, o benchmarking não tem por finalidade refletir e transformar a realidade exterior, mas modificar o comportamento dos próprios atores a partir das liberdades que ele produz e consome. De um lado, sendo públicas, as medidas das atividades quantificadas constrangem os responsáveis a se esforçar para evitar a humilhação dos resultados ruins. Por outro lado, cada 
ação a ser tomada é julgada em termos de fracasso a estigmatizar ou de sucesso a recompensar, o que tem como efeito dessolidarizar os agentes públicos do conjunto da sociedade e esvaziar a percepção de sua função social (Bruno e Didier, 2013). Ao recorrer à quantificação incessante de todas as atividades, segundo os imperativos da "qualidade total" e da "competitividade internacional", o benchmarking "submete os indivíduos a uma disciplina indefinida, destinada a orientar seu engajamento na ação e a governar o que há de mais pessoal: suas iniciativas" (idem: 120).

O novo regime de quantificação pública multiplica os lugares e domínios de produção e uso da informação quantificada, tendo sempre por base a performance das iniciativas estatais e a corresponsabilidade dos atores individuais: meio ambiente, bioética, maltrato infantil, toxicomania, prevenção de doenças sexualmente transmissíveis, proteção das minorias culturais, igualdade de gênero, segurança dos equipamentos domésticos e industriais, normas de qualidade dos bens de consumo. Em cada caso, são elaboradas e negociadas, simultaneamente, as modalidades de julgamento e de formalização estatística desses problemas, a repartição das responsabilidades entre os atores, os meios de avaliação a posteriori das políticas públicas e de sua transformação em função desta avaliação (Desrosières, 2008b).

Cria-se uma circularidade entre a eficiência da ação pública e as performances dos atores individuais, que se reportam cada vez mais ao benchmarking e aos indicadores e cada vez menos ao julgamento baseado nas competências adquiridas, para manter e ampliar sua posição na divisão do trabalho. A quantificação dos fins e dos meios de ação, tanto de profissionais como de consumidores, produz um novo sistema de referência em que os mesmos indicadores e classificações fornecem a equivalência para medir grandezas distintas. Veja-se o caso dos testes de consumo de álcool na direção de veículos, utilizados por policiais e agentes de trânsito como indicador de sua performance. Enquanto os primeiros tendem a avaliar sua eficiência pelo aumento desta cifra, os últimos justificam seu desempenho pela diminuição da mesma (Desrosières, 2014b).

Tratam-se de definições de situações opostas, que resultam do enquadramento dos agentes por objetivos mensuráveis estabelecidos por suas respectivas instituições - polícia e guarda municipal. Os indivíduos são levados a se relacionar com metas fantasmagóricas no lugar das situações concretas de que tomam parte. Diante de um quadro 
de insegurança existencial e danos psicológicos causados pela responsabilização e autovigilância contínuas, tentam maximizar suas oportunidades de ganho, muitas vezes em detrimento do interesse coletivo - paradoxalmente sacrificado pela extrema individualização das condições de trabalho promovida pelo benchmarking.

São numerosos os exemplos em que os agentes buscam enganar com a regra. Na polícia, quando a intenção é "fazer número", abordam-se pequenos traficantes com endereço conhecido. Isso possibilita que os policiais contabilizem tanto a apreensão de droga quanto a detenção de suspeitos e, desse modo, cumpram sua meta semanal, aproveitando-se do fato de que a métrica da operação não distingue o volume da apreensão, tampouco a hierarquia do tráfico. Na mesma linha, temos o expediente de registar um "fato constatado" (ex: roubo de carro) em uma cidade, como o Rio de Janeiro, sendo que o suspeito se localiza em uma outra cidade, como São Paulo. Neste caso, o delegado de polícia de São Paulo pode contabilizar o interrogatório como "fato esclarecido" na cidade, enquanto o Rio de Janeiro ganha um "fato constatado". Inversamente, se o nível da criminalidade encontra-se alto, depondo contra a performance policial, $\mathrm{o}$ delegado pode se recusar a fazer um boletim de ocorrência, demovendo a vítima de sua intenção de registrar queixa (Bruno e Didier, 2013).

Outro fenômeno característico das práticas de contagem da governamentalidade neoliberal é a mudança no estatuto do subjetivo e seu tratamento estatístico. Uma vez que a retroação dos indicadores deixou de ser o efeito não-previsto das técnicas de quantificação para se tornar a finalidade da racionalidade política ancorada no benchmarking, a mensuração da percepção emerge como possibilidade. Categorias de origem, etnia, raça e identidade, antes consideradas "subjetivas demais", tornam-se variáveis privilegiadas em levantamentos e pesquisas. A admissão da autodeclaração e do pertencimento como base suficiente para a contagem de populações indígenas e afrodescendentes evidencia um rompimento com as concepções objetivistas do realismo metrológico prevalecentes desde o século XIX. Aceita-se o caráter construído da identidade para atenuar os fatores externos que incidem sobre o desempenho de grupos minoritários.

A mensuração da percepção subjetiva como base do reconhecimento moral e da existência material dos grupos sociais modifica a luta pela gestão das identidades. Enquanto os movimentos sociais insistem na contagem como forma de resistir e se fazer existir, setores neoconserva- 
dores acusam as classificações oficiais de criarem o racismo ou de impedirem a sua superação. Argumentam que, em vez de promover a coesão e a solidariedade produzidas pela cultura nacional, essas classificações enfatizam clivagens que fragmentam a sociedade (Loveman, 2014).

O avanço da quantificação sobre a vida íntima dos indivíduos produziu uma atitude de desconfiança em relação aos números, especialmente visível na forma como os resultados de censos e pesquisas estatísticas têm sido recebidos, sendo sistematicamente descredibilizados em países com governos neoconservadores e neopopulistas, algo impensável há uma ou duas décadas atrás. De um lado, esse ceticismo foi insuflado à direita, pelo advento da "pós-verdade" e da crise de confiança na ciência, hoje sob ataque de irracionalistas e reacionários. De outro lado, cresce na esquerda o movimento dos que criticam a frieza desumanizante da estatística e a rejeitam por princípio e em bloco, como se a quantificação se encontrasse sempre e necessariamente a favor do Estado e do capital. Trata-se de uma atitude meramente reativa face à "quantomania", a qual, paradoxalmente, acaba reforçando o fetiche pelos números.

Quantificar é produzir saber e reunir poder. Pode ser, portanto, um meio valioso para superar as críticas setoriais e restituir a dimensão do público e do universal, erodidos pelo benchmarking. O statactivisme, neologismo proposto por Bruno, Didier e Prévieux (2014) e inspirado na sociologia da crítica de Boltanski (2009), é um conceito descritivo utilizado para qualificar as diferentes experiências que visam se reapropriar do poder emancipador das estatísticas. Embora seja longa a tradição de uso das estatísticas para garantir demandas por direitos, algumas formas de intervir com números são bastante recentes, especificamente aquelas destinadas a atacar os métodos de dominação característicos da governamentalidade neoliberal:

tratam-se de mobilizações lideradas por leigos, especialistas, ONGs e órgãos de administração local e municipal em reação a critérios de avaliação que percebem como discriminatórios. Em outros casos, o statactivisme não é contra os indicadores, mas consiste em quantificar dados originais para tornar um problema visível e relevante: trabalhadores denunciam a precarização de seus empregos utilizando os números para a defesa de seus direitos; ativistas pró-imigração estimam o custo da política de deportação para mostrar o preço que a sociedade paga por ela. No geral, o uso de estatísticas faz parte do repertório de contendas e é um recurso importante para as mobilizações contemporâneas (Bruno, Didier e Vitale, 2014: 200). 
Bruno, Didier e Prévieux (2014) identificam três modos de lutar com números. O primeiro nível consiste em enganar com a regra, como vimos anteriormente, no caso dos policiais. É o que ocorre quando os atores se apropriam das regras de produção dos dados que servem à autoavaliação para, de maneira mais ou menos aberta, adaptá-las a seus próprios interesses. Temos aqui uma maquiagem dos números, como se verifica quando um empregado de uma empresa utiliza o tempo ou os instrumentos de trabalho para atividades externas à sua função. Entretanto, como se percebe, o enviesamento permite maximizar a autonomia dos agentes contra a dominação a que fazem face; porém, não engendra as condições de sua crítica e reforma.

Já o segundo nível requer um posicionamento deliberadamente crítico e assertivo, que passa por um certo grau de conhecimento da cadeia de produção dos dados e por uma associação de interesses entre atores diversos. Envolve o acesso a um debate ou a uma tribuna pública para acusar uma determinada instituição de quantificar as atividades de seus empregados para deturpar, em vez de realizar, os objetivos que supostamente deveria perseguir. A publicidade é fundamental aqui, seja a de um filme documentário ou a de uma pesquisa sociológica, que revelem, por exemplo, como a baixa das estatísticas criminais não correspondem à maior eficiência do aparato de segurança, podendo ser resultado de manipulações nas codificações realizadas pelas agências de Estado (Silverman, 2014).

Por fim, encontramos a construção estatística de sujeitos coletivos, dotados de interesses e vontade próprios. Mais do que escapar individualmente à autoridade do benchmarking, como no primeiro nível, ou de denunciar as mentiras ocultas em falsas promessas de proteção, como no segundo nível, trata de utilizar as estatísticas para redefinir objetivos perseguidos pelas instituições, com fins emancipatórios. Tal é o caso dos grupos que se reúnem em torno da transformação do conceito estritamente econômico de Produto Interno Bruto (PIB), de maneira a incluir a biodiversidade, o trabalho doméstico e outras formas de riqueza, e, assim, promover a justiça e a promessa de equidade social. Ou, ainda, a utilização de informações estatísticas para impulsionar o movimento pela igualdade de gênero. Eugenia de Rosa (2014) examinou as relações entre associações de defesa de direitos humanos e ONGs que produzem e empregam dados originais sobre violência de gênero. A autora identificou uma rede de uso de números em quatro 
fases de mobilização: no processo de enquadramento e categorização, no desenho e implementação das políticas, nas campanhas de difusão e no monitoramento das oscilações.

Quando as experiências sociais não se enquadram mais nos formatos disponíveis, assistimos a um trabalho político e cognitivo de construção de uma nova categoria compatível com as aspirações de um grupo social. Para ganhar reconhecimento, os grupos têm interesse em se institucionalizar estatisticamente. Tasset (2014) investigou duas tentativas recentes deste tipo. Primeiro, o esforço de alguns cientistas sociais franceses em introduzir a categoria "intelectuais precários", alegando que as nomenclaturas ocupacionais estabelecidas foram forjadas no antigo sistema de proteção social, ora em crise. Este não daria mais conta de explicar o impacto da precarização sobre o grupo de profissionais culturais, que, para eles, reúne pesquisadores, professores, guias de museu, bibliotecários, editores, jornalistas; todos jovens e diplomados, sem estabilidade salarial, cuja grandeza moral estaria ameaçada por um modo de vida crescentemente utilitarista. Para além das situações e competências individuais, a categoria se justificaria contra um novo padrão de funcionamento social que desvaloriza e dociliza o trabalho intelectual em geral.

Em direção oposta a essa estratégia, encontram-se economistas americanos, que agregam jovens com ocupações semelhantes, igualmente diplomados e profissionalmente instáveis, sob a categoria "classe criativa". O que os franceses denunciam como alienante e ambíguo é aqui valorizado como disposição permanente para a inovação. A heterogeneidade social das profissões culturais permite ilustrar, ao mesmo tempo, duas teses opostas: de um lado, um precariado organizado como sujeito político que funda sua unidade na legitimidade cívica; de outro, um grupo de profissionais flexíveis e empreendedores, sempre dispostos a exercer sua liberdade no mercado de trabalho, vendo-se como vanguarda do capitalismo cognitivo. Nos dois casos, cientistas sociais franceses e economistas americanos procuram dotar de consistência os agregados sociais que ajudam a instituir ao quantificá-los (Tasset, 2014).

Além do benchmarking, das estatísticas oficiais e das contagens alternativas realizadas pelos grupos sociais - as duas últimas mobilizadas pelo ativismo estatístico -, encontramos as práticas de autoquantificação e de modelização algorítmica. Não podemos nos deter em sua análise, dados os limites deste artigo, mas esboçaremos uma primeira 
aproximação. Em primeiro lugar, as tecnologias de biosensoriamento e autorastreamento e como elas afetam os sujeitos que as empregam deliberadamente, para monitorar sua performance e atingir os mais variados objetivos: se avaliar (como calcular sua produtividade diária), satisfazer uma curiosidade estética (como visualizar padrões em trajetos através de mapas digitais), resolver problemas (como identificar os alimentos em uma dieta que causem um mal estar frequente), e cultivar hábitos (como programar metas que envolvam esforço físico). Embora possa, por vezes, melhorar a qualidade de vida, a autoquantificação imprime uma nova intensidade à internalização da disciplina. Ao se basear no mapeamento constante do uso do tempo, produz como efeito a conversão voluntária do sujeito em empresário de si mesmo. Além disso, a prática do autorastreamento coloca em relevo uma das questões mais prementes de nosso tempo: a produção de dados que as empresas usam para vender produtos e que os patrões se servem para constranger seus empregados (Berman e Hirschman, 2018).

Já a quantificação algorítmica encontra-se na aplicação de modelos matemáticos à gestão da população. Nesse caso, a circulação massiva de microdados permite acessar territórios, grupos, instituições, mercados e países em frações de segundos. Um saber estatístico automatizado emerge das correlações de informações não previamente selecionadas, não hierarquizadas e altamente heterogêneas, reduzindo a intervenção humana e dispensando hipóteses e convenções sobre o mundo social (Rouvroy, 2014). Aparentemente sem qualquer mediação, a objetividade e a veracidade dos resultados obtidos parecem chegar ao seu grau máximo, pois assume-se que suas hipóteses sejam os próprios dados em circulação. Em consequência, a realidade ganha uma aparência de esfera pública. - porém, controlada por interesses particulares e com governos e empresas coletando quantidades massivas de dados não classificados que podem vir das mais diversas fontes: redes sociais; blogs; feeds de notícias; sensores de faces, sons e imagens; e-mails; jogos; geolocalizadores e autorizações de celulares; sistemas de cartões; operações de marketing e publicidade; pesquisas científicas; redes e sistemas de segurança, etc. (Teles, 2018: 435).

A principal questão colocada pelas operações algorítmicas é a geração de mecanismos de controle sem a necessidade de apoio em discursos e ideologias. Produz-se uma verdade, descolada das convenções sociais, que não pode ser objeto de debates ou discordâncias a não ser em bolhas fechadas e direcionadas. Um fenômeno particularmente 
perverso quando considerada a implementação e o monitoramento de políticas. Esse é o caso dos modelos que preveem as chances de recidiva criminal - que utilizam métodos secretos e baseados em fatores como raça, classe, origem e outras clivagens sociais. Como mostrou estudo de O’Neil (2017), um desses modelos prevê que um preso de um bairro pobre e altamente policiado tenha maior probabilidade de ser encarcerado novamente, o que justificaria seu confinamento por mais tempo. Ao deixar a prisão e retornar a seu bairro, a chance de reincidir aumentaria, face ao período ampliado passado no ambiente prisional. Ou seja, a saída da prisão torna-se a confirmação da previsão de que infratores deste bairro reincidirão. A eficácia de um tal modelo reside em seus efeitos recursivos sobre a realidade, que acentuam as distorções da justiça criminal em vez de corrigi-las.

Assim, o big data se caracteriza pela automação estatística em relação às convenções, escapando às disputas de uma esfera pública que se torna opaca e balizando inúmeras decisões de governos e empresas que esvaziam os canais de deliberação democrática. Partilha com o benchmarking a racionalidade política que repousa sobre a coleta, agregação e análise descentralizada de dados, com o fim de modelizar, antecipar e afetar comportamentos. Eis a principal característica da quantificação no neoliberalismo, que, à diferença dos regimes de governo anteriores, promove a interação entre agentes sociais e tecnologias autônomas para torná-los sujeitos da sua própria observação e classificação: monitores de suas sociabilidades.

\section{CONSIDERAÇÕES FINAIS}

Como agir ou reagir, no governo neoliberal, quando os números se tornam simultaneamente fonte de dominação e instrumento da luta pela emancipação? Por um lado, os indicadores de performance depõem as competências de avaliação e julgamento dos atores em situações consideradas únicas e singulares, portanto, incomensuráveis. Por outro, o ativismo estatístico reivindica a generalização da comensuração para espaços antes não quantificáveis (biodiversidade, percepções subjetivas, formas de trabalho não-remunerado, participação no consumo cultural), em nome da ampliação dos bens coletivos e da denúncia das desigualdades do capitalismo avançado. Entre um polo e outro encontramos as práticas de autoquantificação, uma atividade livremente escolhida que, a depender do caso e do uso, pode tanto aumentar o controle quanto gerar recursos que 
melhorem a qualidade de vida. Como advertiu Desrosières, tratam-se de atitudes aparentemente distantes e irreconciliáveis, que podem ser aproximadas por uma estratégia de análise das relações entre os modos de pensar a sociedade, as maneiras de agir sobre ela e a quantificação adequada em cada caso. Essa abordagem permite colocar em evidência não apenas as formas de governamentalidade, mas também as modalidades de sua crítica (2014b: 57).

As formas hegemônicas e excludentes de quantificação obrigam os cientistas sociais a sofisticar seu olhar sobre os números como o elo privilegiado entre o Estado, a ciência e a vida pública. Afinal, a monopolização dos dados enquanto recursos sobre coisas e sobre pessoas não é um problema crescente apenas para os cidadãos, mas também uma ameaça à infraestrutura do conhecimento social. Em vez de interesses ocultos e privados, padrões científicos debatidos publicamente devem fornecer a base de contagens, medidas e categorias que permitam valorar e coordenar questões de interesse comum. Esta talvez seja a forma mais urgente e negligenciada de democratizar a soberania no presente: qualificando, pela experiência política e pela deliberação pública, as liberdades e autonomias que o benchmarking e o algoritmo prometem incentivar; mas que ao submetê-las a uma disciplina indefinida de avaliação comparativa acabam, ao contrário disso, capturando e esvaziando.

Por sua vez, o ativismo estatístico permite colocar em questão a realidade e abrir caminho para outros devires, sob a condição de não rejeitarmos o poder emancipador da quantificação em favor de uma pretensa superioridade das qualidades e das singularidades sobre as quantidades. Contra a gaiola de ferro da razão econômica, um "outro número" é a entrada para um "outro mundo" (Didier e Tasset, 2013: 138). A construção estatística de novos sujeitos coletivos e as reações contra instituições acusadas de quantificar as atividades de seus funcionários para deturpar os objetivos que supostamente deveriam perseguir constituem formas inéditas de democratização da soberania. A categorização contra-hegemônica e o contradiscurso numérico promovem uma luta que, como sugeriu Foucault (2000), passa cada vez menos pela mediação dos intelectuais e dos porta-vozes da consciência, abrindo espaço para a multiplicidade polifônica e para a ação em rede que já não é mais dirigida por partidos, sindicatos e corporações. 
A sociologia da crítica de Boltanski, que inspirou os últimos trabalhos de Desrosières (2008b, 2014b), e os mais recentes de Bruno e Didier $(2013,2014)$, nos permitiu ter uma compreensão mais fina da agência e das categorias sobre as quais repousam as tentativas voluntaristas de modificar as bases da contabilidade social. Nessa chave, as estatísticas conferem forma institucional a aspirações e inquietações dispersas, possibilitando a formação de sujeitos coletivos mobilizados por diferentes sensos de justiça e pela autenticidade de suas reivindicações. Tal entendimento ilumina as modalidades de crítica que correspondem a diferentes tipos de estatística e que levam à reforma e à emancipação.

A partir desse feixe de questionamentos, o artigo introduz o conceito de "regimes políticos de quantificação", inspirando-nos nas contribuições de Foucault e Desrosières, com o fim de precisar quais os níveis da agência e da vida social foram construídos progressivamente como domínios de comensuração. No Estado Liberal, esse domínio é o mercado, construído como espaço de veridição e de realização da justiça - o que supõe a disponibilização pública de informações iguais aos diferentes atores econômicos, que, assim, orientam seu comportamento pelas estatísticas de produção e de preço. No Estado Providencial, a construção do trabalho como esfera social passa pela criação estatística do desemprego e do desempregado, e sua vinculação a efeitos jurídicos concretos. Viabilizando, com isso, a indexação dos salários e a responsabilidade solidária entre patrões, sindicatos, empregados, burocratas e analistas sociais, que passam a traduzir seus interesses com base em estatísticas de custo de vida e de acidentes de trabalho. No Estado Keynesiano, a pesquisa por amostragem permite generalizar os índices de preço e de consumo familiar - até então restritos aos trabalhadores assalariados - para o conjunto da população. Além disso, cria um espaço global de monitoramento da economia através da otimização do PIB, de cujo desempenho passa a depender a construção da crise econômica como fato social.

Finalmente, no Estado Neoliberal a retroação dos indicadores se torna a finalidade da racionalidade política ancorada no benchmarking e no big data, promovendo, inclusive, a mensuração da percepção (sobre a identidade, a origem, a etnia e a raça) como meio de reformar a conduta e induzir a agência social. Por sua vez, a tradição de reforma e luta contra a desigualdade, antes verticalizada pelo Estado como garantidor da vida pública, ressurge de forma ampliada com o ativismo estatístico dos movimentos sociais. Já as práticas de quantificação produzem um 
sujeito de novo tipo, que não mais se observa pela singularidade de suas experiências, mas pelas representações abstratas dos dados que ele mesmo produz, em uma nova forma de autoconhecimento por meio dos números.

O século XIX foi marcado pelo entusiasmo despertado com a criação dos rankings internacionais que, prometendo elevar o progresso e a coesão moral das sociedades, mediam e comparavam os desempenhos de povos e nações por meio de indicadores de industrialização, urbanização, salubridade e instrução. O século XXI nasce sob o signo da desconfiança em relação ao avanço da quantificação sobre a vida íntima e cotidiana dos indivíduos. Pressionados por metas e objetivos de performance, obrigados ao monitoramento constante dos riscos implicados em nossa vida alimentar e familiar, sexual e afetiva, médica e escolar, profissional e pessoal, somos confrontados com o desconforto de quem deve agir e decidir com base em planilhas de produção, tabelas de gastos, apólices de seguro, estatísticas de acidentes, sondagens de opinião, exames laboratoriais e testes ergométricos: uma infinidade de dispositivos de quantificação que definem nossa imagem de fracasso e de sucesso, bem como o medo e a ansiedade que lhes correspondem. Entre o otimismo romântico do passado e o ceticismo pós-humanista do nosso tempo, cabe uma terceira atitude em relação aos números. Uma atitude que nos permita perceber a relação entre os modos como somos levados a nos conhecer e o modo como somos levados a nos governar, abrindo espaço para criticar as categorias com que pensamos e representamos a realidade e com que desejamos e praticamos a liberdade.

(Recebido para publicação em 30 de novembro de 2019)

(Reapresentado em 15 de agosto de 2020)

(Reapresentado em 10 de novembro de 2020)

(Reapresentado em 23 de fevereiro de 2021)

(Aprovado para publicação em 9 de março de 2021)

\section{NOTAS}

1. Estatístico e administrador no Institut National de la Staistique et des Études Économiques (INSEE), onde participou diretamente da reforma do sistema de nomenclaturas e categorias profissionais, mas também sociólogo, pesquisador e orientador de teses na École des Hautes Études en Sciences Sociales (EHESS), Alain Desrosières foi um articulador de fronteiras disciplinares, e sua perspectiva de análise é marcada por esse hibridismo. Desde os anos 1970, se esforçou, de um lado, para instituir junto aos estatísticos uma 
cultura reflexiva quanto às dimensões históricas e socialmente situadas dos instrumentos de sua prática; de outro lado, exortou sempre os cientistas sociais a não negligenciarem a natureza técnica da quantificação. Esse esforço se mostrou, desde cedo, em seu projeto de fazer uma história política e administrativa da produção de dados - nesse primeiro momento, ainda não sociológica. Vale destacar os dois volumes de Pour une histoire de la statistique, resultado dos colóquios que organizou em 1976 e que reuniram diversos historiadores dos Annales, como Jean-Claude Perrot, Michele Perrot e Jacques Ozouf. Sobre o legado intelectual de Alain Desrosières, conferir a coletânea organizada por Bruno, Jany-Catrice e Touchelay (2016).

2. O texto foi retomado e ampliado diversas vezes pelo autor. Sua primeira versão apareceu em 2000, no Courrier des Statistiques. Foi seguida de um verbete na Cambridge History of Science (2001), de um capítulo na coletânea Historicités de l'action publique (2003) e, finalmente, por capítulo de seu livro Pour une sociologie historique de la quantification (2008). É essa última edição que tomamos como referência em nossa análise do argumento (Armatte, 2014: 21).

3. À exceção do Estado Engenheiro, que, além de historicamente fluido, é estadocêntrico e, portanto,, refratário à modulação da agência social, aspecto que nos interessa mais diretamente.

4. Internacionalismo estatístico é o termo pelo qual ficou conhecido na historiografia o movimento de mundialização e padronização da produção estatística, a partir das convenções emanadas de decisões colegiadas em espaços especializados - os chamados Congressos Internacionais de Estatística, realizados de 1853 a 1876, que debatiam as questões fundamentais da prática estatística, tais como a normalização das classificações, a precisão na definição das categorias, a clareza dos questionários e os procedimentos que convinham à sua aplicação (Brian, 1999: 15-22).

5. A amostragem estratificada aleatória foi introduzida pioneiramente na pesquisa de desemprego do Census Bureau americano, em 1936, pelas mãos de Morris Hansen e Edwards Deming. No pós-guerra, difundiu-se entre as instituições estatísticas nacionais, promovendo profundas transformações no nível do discurso, das representações e do trabalho estatísticos, analisadas por Beaud e Prévost (2010: 37-65). 


\section{REFERÊNCIAS}

ALBERTI, Manfredi. (2011), "The Birth of Unemployment Statistics: a Comparison (1880-1914)", in EUROPEAN CONGRESS ON WORLD AND GLOBAL HISTORY, 3th, 2011, Londres. London School of Economics and Political Science. Disponível em: <http:/ /www.academia.edu/5365929/The_birth_of_unemployment_statistics_a_comparison_1880-1914>. Acesso em: 02 jun. 2021.

ARMATTE, Michel. (2014), "Introduction aux Travaux d'Alain Desrosières: Histoire et Sociologie de la Quantification". Statistique et Société, v. 2, n. 3, pp. 17-23.

BEAUD, Jean-Pierre; PRÉVOST, Jean-Guy. (2010), “L'Histoire de la Statistique Canadienne dans une Perspective Internationale et Panaméricaine", in N.C. Senra e A.P.R. Camargo (orgs.). Estatísticas nas Américas: por uma agenda de estudos históricos comparados. Rio de Janeiro, IBGE, pp. 37-65.

BERMAN, Elizabeth; HIRSCHMAN, Daniel. (2018), “The Sociology of Quantification: Where Are We Now?", Contemporary Sociology, v. 47, n. 3, pp. 257-266.

BOLTANSKI, Luc. (2009), De la Critique: Précis de Sociologie de l’Émancipation. Paris, Éditions Gallimard.

. (2014), "Quelle Statistique pour Quelle Critique?", in I. Bruno, E. Didier e J. Prévieux. Statactivisme: Commment Lutter avec des Nombres.Paris, La Découverte, pp. 33-50.

BOLTANSKI, Luc; THÉVENOT, Laurent. (1991), De la Justification: les Économies de la Grandeur. Paris, Éditions Gallimard.

BRIAN, Éric. (1999), “Del Buen Observador al Estadístico del Estado: la Mundialización de las Cifras". Anuario IEHS, v. 14, pp. 15-22.

BRUNO, Isabelle; DIDIER, Emmanuel. (2013), Benchmarking: 1'État sous Pression Statistique. Paris, La Découverte.

BRUNO, Isabelle; DIDIER, Emmanuel; PRÉVIEUX, Julien (orgs.). (2014), Statactivisme: Comment Lutter avec des Nombres. Paris, La Découverte.

BRUNO, Isabelle; DIDIER, Emmanuel; VITALE, Tommaso. (2014b), "Statactivisme: Forms of Action between Disclosure and Affirmation", Partecipazione e Conflitto, v. 7, n. 2, pp. 198-220.

BRUNO, Isabelle; JANY-CATRICE, Florence; TOUCHELAY, Béatrice (eds). (2016), The Social Sciences of Quantification: from Politics of Large Numbers to Target-Driven Policies. Heidelberg, Springer.

CAMARGO, Alexandre de Paiva Rio. (2016), A construção da medida comum: estatística e política de população no Império e na Primeira República. Tese (Doutorado em Sociologia), Universidade do Estado do Rio de Janeiro, Rio de Janeiro.

CAMARGO, Alexandre de Paiva Rio; DANIEL, Claudia. (2021), "Os estudos sociais da quantificação e suas implicações na sociologia". Sociologias, v. 23, n. 56, no prelo.

DE ROSA, Eugenia. (2014), "Gender Statactivism and NGOs. Development and Use of Gender Sensitive-Data for Mobilizations and Women's Rights", Partecipazione e Conflitto, v. 7, n. 2, pp. 314-347.

DEAN, Mitchell. (1999), Governmentality: power and rule in modern society. Londres, Sage. 
DESROSIÈRES, Alain. (1988), “La Partie pour le Tout: Comment Généraliser? La Préhistoire de la Contrainte de Répresentativité". Statistique et Analyse des Données, v. 13, n. 2, pp. 93-112. . (1993), La Politique des Grands Nombres: Histoire de la Raison Statistique. Paris, La Découverte. . (2008a), "Introduction", in Pour une Sociologie Historique de la Quantification. Paris, Presses de l'École des Mines, pp. 7-20.

. (2008b), "Historiciser l'Action Publique: 1'État, le Marché et les Statistiques", in Pour une Sociologie Historique de la Quantification. Paris, Presses de l'École des Mines, pp. 39-56.

(2014a), "La Statistique, Outil de Libération ou Outil de Pouvoir", in I. Bruno, E. Didier e J. Prévieux. Statactivisme: Commment Lutter avec des Nombres. Paris, La Découverte, pp. 51-66.

. (2014b), "Le Gouvernement de la Cité Néolibérale: Quand la Quantification Rétroagit sur les Acteurs", in . Prouver et Gouverner: une Analyse Politique des Statistiques Publiques. Paris, La Découverte, pp. 33-59.

DESROSIÈRES, Alain; KOTT, Sandrine. (2005), “Quantifier”. Genèses, v. 58, n. 1, pp. 2-3.

DESROSIÈRES, Alain; THÉVENOT, Laurent. (1988), Les Catégories Socioprofessionnelles. Paris, La Découverte.

DIAZ-BONE, Rainer; DIDIER, Emmanuel. (2016), “The Sociology of Quantification: Perspectives on an Emerging Field in the Social Sciences". Historical Social Research, v. 41, n. 2, pp. 7-26.

DIDIER, Emmanuel; TASSET, Christian. (2013), "Pour un Statactivisme: la Quantification comme Instrument d'Ouverture du Possible". Revue des Sciences Humaines, n. 24, pp. 123-140.

DONZELOT, Jacques. (1994), L'Invention du Social: Essai sur le Déclin des Passions Politiques. Paris, Éditions du Seuil.

ELIAS, Norbert. (1993), O Processo Civilizador: Formação do Estado e Civilização. Rio de Janeiro, Jorge Zahar Editor.

ESPELAND, Wendy; STEVENS, Mitchell. (2008), "The Sociology of Quantification". Archives Européennes de Sociologie, v. 49, n. 3, pp. 401-436.

FOUCAULT, Michel. (2000), "Os Intelectuais e o Poder", in Microfísica do poder. $15^{\mathrm{a}}$ ed. Rio de Janeiro, Graal. (2008), Segurança, Território, População. São Paulo, Martins Fontes. (2009), O Nascimento da Biopolítica. São Paulo, Martins Fontes.

GAGNON, Marc-André. (2000), "Les Réseaux de 1’Internationalisme Statistique”, in J.P. Beaud e J.G. Prévost (orgs.). L'Ère du Chiffre: Systèmes Statistiques et Traditions Nationales. Quebec, Presses de 1’Université du Québec, pp. 189-219.

HACKING, Ian. (1982), "Biopower and the Avalanche of Printed Numbers". Humanities in Society, n. 5, pp. 279-295.

LATOUR, Bruno. (1988), The Pasteurization of France. Cambridge, Harvard University Press. 
. (2000), Ciência em Ação: Como Seguir Cientistas e Engenheiros Sociedade Afora. São Paulo, Editora Unesp.

LOVEMAN, Mara. (2014), National Colors: Racial Classification and the State in Latin America. Nova Iorque, Oxford University Press.

MILLER, Peter. (2001), "Governing by Numbers: Why Calculative Practices Matter". Social Research, v. 68, n. 2, pp. 379-396.

NEIBURG, Federico. (2011), “La Guerre des Indices. L'inflation au Brésil (1964-1994)”. Genèses, n. 84, pp. $25-46$.

O’NEIL, Cathy. (2017), Weapons of Math Destruction: How Big Data Increases Inequality and Threatens Democracy. Nova Iorque, Crown.

OTERO, Hernán. (2006), Estadística y Nacíon: Una Historia Conceptual del Pensamiento Censal de la Argentina Moderna, 1869-1914. Buenos Aires, Prometeo libros.

ROSE, Nikolas. (1999), Powers of Freedom: Reframing Political Thought. Cambridge, Cambridge University Press.

ROSE, Nikolas; MILLER, Peter. (1992), "Political Power Beyond the State: Problematics of Government". British Journal of Sociology, v. 43, n. 2, pp. 172-205.

ROUVROY, Antoinette. (2014), “BigData: de Nouveaux Outils à Combiner aux Savoirs Établis et à Encadrer par la Délibération Publique". Statistique et Société, v. 2, n. 4, pp. 33-41.

SILVERMAN, Eli. (2014), "Les Jeux de la Police avec les Taux de Criminalité", in I. Bruno, E. Didier e J. Prévieux. Statactivisme: Commment Lutter avec des Nombres. Paris, La Découverte, pp. 75-87.

TASSET, Cyprien. (2014), “Les 'Intellos-Précaires' et la Classe Créative: le Recours à la Quantification Dans Deux Projets Concurrents de Regroupement Social", in I. Bruno, E. Didier e J. Prévieux. Statactivisme: Commment Lutter avec des Nombres. Paris, La Découverte, pp. 117-132.

TELES, Edson. (2018), “Governamentalidade Algorítmica e as Subjetivações Rarefeitas”. Kriterion, n. 140, pp. 429-448.

THÉVENOT, Laurent. (1986), "Les Investissements de Forme”, in L. Thévenot (ed.). Conventions Économiques. Paris, Presses Universitaires de France, pp. 21-71. 


\section{RESUMO \\ Estado, Quantificação e Agência: Uma Análise Genealógica}

O artigo investiga o papel das práticas de quantificação na construção do Estado e das rotinas sociais, nas formas de governar a população através dos números, nas modalidades de crítica estatística da realidade e nos processos de mudança social. Procuramos contribuir com uma síntese original de duas matrizes interpretativas: de um lado, os estudos anglo-foucaultianos sobre a governamentalidade, que relacionam as formas de quantificação a outras tecnologias de indução das condutas, no liberalismo e no neoliberalismo - "regimes de governo" que produzem e consomem liberdades. De outro lado, a sociologia pragmática francesa, em particular o conceito de "convenções de equivalência" e a ideia de pluralidade das lógicas de ação, que permitem compreender a dupla natureza da estatística como "instrumento de prova" e como "instrumento de governo", formulada por Alain Desrosières, que prioriza a ciência dos números e seu papel na coordenação da vida social. Propomos um uso crítico desses modelos, ensaiando uma genealogia dos níveis da agência e da vida social que foram construídos progressivamente como domínios de mensuração. Tal opção permite explicitar a singularidade das práticas de quantificação no mundo contemporâneo, examinadas em seus quatro gêneros principais: o benchmarking, o ativismo estatístico, o autorrastreamento e a política dos algoritmos.

Palavras-chave: sociologia da quantificação; sociologia do estado; governamentalidade; neoliberalismo; gestão da população

\section{ABSTRACT \\ State, Quantification and Agency: A Genealogical Analysis}

This article investigates the role of quantification practices in the construction of the State and social routines, in the ways of governing the population through numbers, in the modalities of statistical criticism of reality, and in the processes of social change. We seek to contribute with an original synthesis of two interpretative matrices: on the one hand, Anglo-Foucauldian studies on governmentality, which relate the forms of quantification to other technologies of induction of conduct, in liberalism and neoliberalism, "government regimes" that produce and consume freedoms. On the other hand, French pragmatic sociology, in particular the concept of "equivalence conventions" and the idea of a plurality of logics of action, allow us to understand the dual nature of statistics as an "instrument of proof" and as an "instrument of government", formulated by Alain Desrosières, which prioritizes the science of numbers and its role in the coordination of social life. We propose a critical use of these models, rehearsing a genealogy of levels of 
agency and social life progressively constructed as measurement domains. This choice makes it possible to explain the singularity of quantification practices in the contemporary world, examined in its four main categories: benchmarking, statistical activism, self-tracking, and the politics of algorithms.

Keywords: Sociology of Quantification; Sociology of the State; Governmentality; Neoliberalism; Population Management.

\section{RÉSUMÉ \\ État, Quantification et Agence: Une Analyse Généalogique}

Cet article interroge le rôle des pratiques de quantification dans la construction de l'État et des routines sociales, dans les manières de gouverner la population par les nombres, dans les modalités de critique statistique de la réalité et dans les processus de changement social. Nous cherchons à contribuer à une synthèse originale de deux matrices interprétatives: d'une part, les études anglo-foucaultiennes sur la gouvernementalité, qui rattachent les formes de quantification à d'autres technologies d'induction de conduite, dans le libéralisme et le néolibéralisme - les « régimes de gouvernement » qui produit produisent et consomment des libertés; d'autre part, la sociologie pragmatique française, en particulier le concept de « conventions d'équivalence » et l'idée de pluralité des logiques d'action, qui permettent de comprendre la double nature de la statistique comme « instrument de preuve » et comme " instrument de gouvernement », formulé par Alain Desrosières, qui privilégie la science des nombres et son rôle dans la coordination de la vie sociale. Nous proposons une utilisation critique de ces modèles, en répétant une généalogie des niveaux d'agence et de vie sociale qui ont été progressivement construits comme domaines de mesure. Cette option permet d'éclairer l'unicité des pratiques de quantification dans le monde contemporain, examinées dans leurs quatre grands genres: benchmarking, activisme statistique, self-tracking et politique algorithmique.

Mots-clés: Sociologie de la Quantification; Sociologie de l’État; Gouvernementalité; Néolibéralisme; Gestion de la Population. 


\section{RESUMEN}

Estado, Cuantificación y Agencia: Un Análisis Genealógico

El artículo investiga el papel de las prácticas de cuantificación en la construcción del Estado y de las rutinas sociales, en las formas de gobernar a la población a través de los números, en las modalidades de crítica estadística de la realidad y en los procesos de cambio social. Buscamos contribuir a una síntesis original de dos matrices interpretativas: por un lado, los estudios anglo-foucaultianos sobre la gubernamentalidad, que vinculan las formas de cuantificación con otras tecnologías de inducción de las conductas, liberalismo y en el neoliberalismo - "regímenes de gobierno" que producen y consumen libertades. Por otra parte, la sociología pragmática francesa, en particular el concepto de "convenciones de equivalencia" y la idea de pluralidad de las lógicas de acción, que permiten comprender la doble naturaleza de la estadística como "instrumento de prueba" y como "instrumento del gobierno", formulada por Alain Desrosières, que prioriza la ciencia de los números y su papel en la coordinación de la vida social. Proponemos un uso crítico de estos modelos, ensayando una genealogía de los niveles de agencia y de la vida social que fueron construidos progresivamente como dominios de medición. Esta opción permite la singularidad de las prácticas de cuantificación en el mundo contemporáneo, examinadas en sus cuatro géneros principales: el benchmarking, el activismo estadístico, el auto rastreo y la política de los algoritmos.

Palabras-clave: sociología de la cuantificación; sociología del estado; gubernamentalismo; neoliberalismo; gestión de la población. 